\title{
Long-term Complications of Posterior Chamber Phakic Refractive Lenses Case Report and Literature Review
}

\author{
X-P Chen, F Yuan, Y-Z Yuan, Q-L He
}

\begin{abstract}
This article presents two cases of phakic refractive lens (PRL) complications in China. Case 1 presents a highly myopic patient with PRL's footplate partly subluxated into the anterior cham-ber by blunt trauma one-year after implantation. The PRL was repositioned successfully without other complications. Case 2 represents a case of pigment dispersion glaucoma that developed seven years after PRL implantation. Intraocular pressure (IOP) lowering therapy was initiated and the IOP contin-ued to be in the normal range for both affected eyes with ongoing follow-up. In summary, a comprehen-sive ophthalmic evaluation is essential to optimize both patient and PRL selection to minimize the risk of potential complications and PRL implantation warrants long-term follow-up.
\end{abstract}

Keywords: Anterior subluxation, glaucoma, high myopia, phakic refractive lens

\section{Complicaciones a Largo Plazo de los Lentes Refractivos Fáquicos de Cámara Posterior: un Reporte de Caso y Revisión de la Literatura}

\author{
X-P Chen, F Yuan, Y-Z Yuan, Q-L He
}

\begin{abstract}
RESUMEN
Este artículo presenta dos casos de complicaciones de lentes refractivos fáquicos (LRF) en China. El caso 1 presenta a un paciente altamente miope con reposapiés de LRF parcialmente subluxada en la cámara anterior por un traumatismo contuso un año después de la implantación. El LRF se reposicionó con éxito sin otras complicaciones. El caso 2 representa un caso de glaucoma de la dispersión del pigmento desarrollado siete años después de la implantación del LRF. Se inició la terapia para disminuir la presión intraocular (PIO), y la presión intraocular continuó en el rango normal para ambos ojos afectados con seguimiento permanente. En resumen, una evaluación oftálmica integral es esencial para optimizar la selección tanto del paciente como del LRF, con el fin de minimizar el riesgo de potenciales complicaciones y seguimiento a largo plazo de la garantía del implante de LRF.
\end{abstract}

Palabras claves: Subluxación anterior, glaucoma, alta miopía, lentes refractivos fáquicos

West Indian Med J 2017; 66 (1): 180

\section{INTRODUCTION}

Implantation of intraocular lenses in the phakic eye (pIOL) is a relatively new technique to correct high ametropias (1). In 2001 , implantation of posterior chamber (PC) pIOL known as the Phakic refractive lens was reported(2). In our institution, we started to implant the PRL (Baikang surgical, Chekiang,

From: Department of Ophthalmology, Zhongshan Hospital, Fudan University, Shanghai 200032, China.

Correspondence: Dr F Yuan, Department of Ophthalmology, Zhongshan Hos-pital, Fudan University, Shanghai 200032, China. Email: feiyuancn@ 126.com
China) which was made of silicone to treat high myopia. The phalic refractive lens has proven to be a safe and effective procedure to correct moderate to high myopia in most eyes (3). Because of the proximity of the PRL to the crystalline lens, complications of PRL implantation such as cataract formation, endothelial cell loss (4), pigmentary glaucoma (5), pupillary block $(6,7)$ and dislocation into the vitreous cavity $(2)$ had been reported, and the rate of complications was expected to increase with time. Nevertheless, to the best of our knowledge, there has been no previous case report on PRL long-term complication in China. We hereby report two cases of complica- 
tions that happened one and seven years after the implantation, followed by a thorough literature review.

\section{CASE REPORT}

\section{Case 1}

A 54-year-old woman visited our hospital complaining of blurred vision in her right eye in 2012 and reported suffering blunt trauma in that eye from a person's elbow on a crowded bus one month previously. Her previous ocular records revealed that she had undergone bilateral implantation of a posterior chamber phakic intraocular lense with a horizontal length of $11.3 \mathrm{~mm}$ to correct -10.0 diopter (D) in the right eye and $-9.0 \mathrm{D}$ in the left eye, with good visual outcomes after surgery in 2006. The preoperative best-corrected visual acuity (BCVA) was 20/20 in the right eye. The white-to-white (WTW) distance measured by IOLMaster partial coherence interferometry (PCI) platform (Carl Zeiss meditec, Jena, Germany) was $12.6 \mathrm{~mm}$, the anterior chamber depth (ACD) was $3.47 \mathrm{~mm}$, and the corneal endothelial cell counts measured by a Specular Microscope SP 2000P (Topcon, Japan) were 2970 cells $/ \mathrm{mm}^{2}$. The intraocular pressure (IOP), measured by Goldmann applanation tonometry, was $12.7 \mathrm{mmHg}$.

On examination, the uncorrected distance visual acuity (UDVA) was 20/40 and BCVA was 20/20 in the right eye. The slit-lamp revealed that the nasal portion of the PRL was subluxated into the anterior chamber of the right eye (Fig.1A).

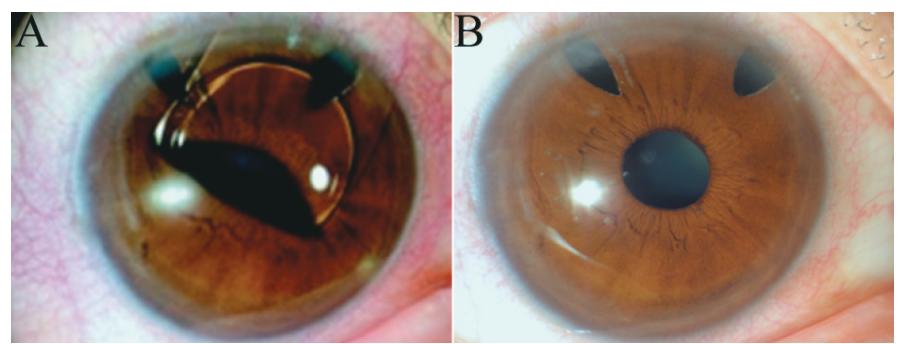

Fig. 1 A: Case 1, the PRL's footplate partly subluxated into the anterior chamber in the right eye after a blunt trauma one-year after the PRL implantation.

B: Case 1, the PRL was centered and the crystalline lens was clear two years after surgery.

The cornea was clear and the anterior chamber was deep and quiet. It showed the patient's bilateral superior surgical peripheral iridectomies. The crystalline lens was clear. Examination through a dilated pupil showed no evidence of zonular dehiscence or phacodonesis. The IOP was $15.3 \mathrm{mmHg}$ and WTW distance was $12.6 \mathrm{~mm}$ in her right eye. This study was conducted in accordance with the Declaration of Helsinki and with approval from the Ethics Committee of Fudan University. Written informed consent was obtained from participants.

After informed consent was obtained, a $6.0 \mathrm{~mm} 12$ O'clock clear corneal approach was performed under peribul- bar anaesthesia (lidocaine 2\% and bupirainum $0.5 \%$ ) after pupillary dilation. Viscoelastic substances were used to create the necessary working space within the anterior chamber and to protect the corneal endothelial cells. The subluxated foot-plate was replaced beneath the iris with a spatula and the PRL was centred. Carbamylcholine was injected to constrict the pupil. Postoperatively, topical tobramycin $0.3 \%$ and dexam-ethasone $0.1 \%$ (Tobradex; Alcon Pharmaceuticals, Fort Worth, Texas, USA) were given four times daily for two weeks in the right eye.

First day postoperatively, the slit-lamp examination showed a centred PRL and the UDVA was 20/20. The IOP was $14.2 \mathrm{mmHg}$ and the endothelium cell counts were 2811 cells $/ \mathrm{mm}^{2}$. The crystalline lens was clear. The manifest refraction remained unchanged, throughout the 24-month follow-up period (Fig. 1B).

\section{Case 2}

A 38-year-old man presented with a history of gradually declining visual acuity for one-year in his left eye. He had undergone bilateral PRL implantation for treatment of high myopia in both eyes in 2006. The records showed that prior to the surgeries, the manifest refraction indicated myopia of $-11.25 \mathrm{D}$ and an astigmatism of $-1.00 \mathrm{D}$ in his right eye, $-10.25 \mathrm{D}$ and an astigmatism of $-1.25 \mathrm{D}$ in his left eye. The ACD was $3.94 \mathrm{~mm}$ and $3.93 \mathrm{~mm}$, respectively in his right and left eyes. Octopus visuals field tests (Haag-streit, Switzerland) were normal in both eyes. Intraocular pressure was $17 \mathrm{mmHg}$ in the right eye and $19 \mathrm{mmHg}$ in the left eye, respectively. The patient was otherwise healthy and without a familial history of glaucoma.

Examination revealed IOP of $24.3 \mathrm{mmHg}$ in the right eye and $26.1 \mathrm{mmHg}$ in the left eye, respectively. The patient's UDVA was 20/20 in both eyes. We observed shallow anterior chambers, clear lenses, as well as the bilateral superior surgical peripheral iridectomies. The anterior chamber angles were grade 1 of the Scheie grading system for both eyes. Gonioscopy revealed dense, 3+ pigmentation of the anterior chamber angles 360 degrees, left eye $>$ right eye. The pigmentary dispersion was observed on the anterior and posterior surface of the PRL. Fundus examination revealed a cup-to-disc ratio of 0.5 and 0.6 in the right eye and left eye, respectively. Octopus visual field tests demonstrated a general depression of retinal sensitivity in the right eye and nasal defect in the left eye. Ultrasound biomicroscopy SW3200L (UBM, Suoer, China) showed narrow angles and anterior rotation of the irisciliary bodies in both eyes, with the centre depth of the anterior chamber $2.54 \mathrm{~mm}$ in the right eye and $2.61 \mathrm{~mm}$ in the left eye, respectively. The PRL vault was $0.42 \mathrm{~mm}$ in the right eye, and $0.26 \mathrm{~mm}$ in the left eye (Fig. 2).

The retinal nerve fibre layer (RNFL) thickness assessed by a spectral domain optical coherent tomography [SD-OCT] (Carl Zeiss Meditec, Dublin, CA, USA) showed that the RNFL 


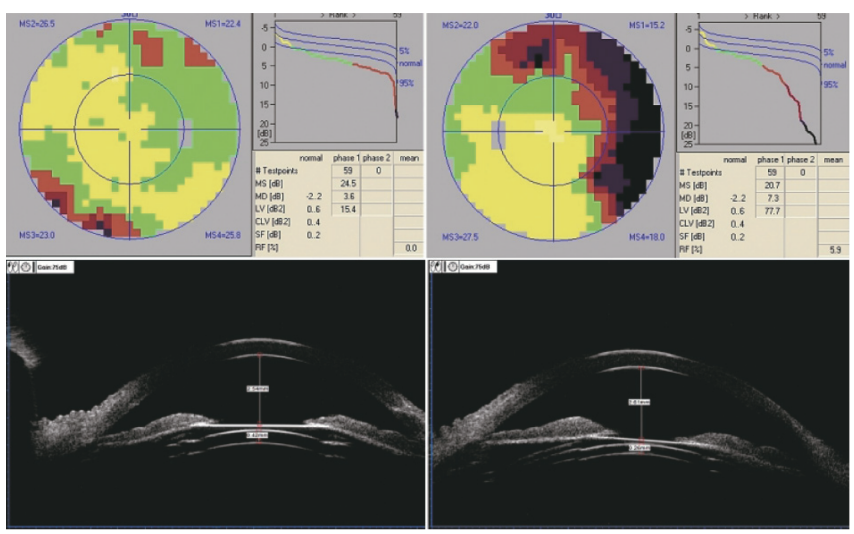

Fig. 2: Case 2, octopus visual field tests and ultrasound biomicroscopy seven years after the RPL implantations. A general depression was found in the right eye (top right) and nasal defect in the left eye (top left). Ultrasound biomicroscopy narrow angles, anterior rotation of the iris-ciliary bodies, and shallow anterior chambers in both eyes. The PRL vault was $0.42 \mathrm{~mm}$ and $0.26 \mathrm{~mm}$ in both eyes, respectfully.

was thin in both eyes, especially in left eye. Intraocular pressure-lowering therapy was initiated with topical carteolol hydrochloride $2 \%$ every 12 hours and brimonidine tartrate $0.1 \%$ every eight hours. The IOP decreased to $18 \mathrm{mmHg}$ and 20 $\mathrm{mmHg}$, respectively. The IOP continued to be in the normal range for both eyes with ongoing follow-up. The progression of visual field defects had been halted. The patient continues to be monitored closely for glaucoma.

\section{DISCUSSION}

This article presents two cases of PRL complications. Case 1 presents a highly myopic patient with PRL partly subluxated into the anterior chamber after an ocular trauma one-year after implantation. It showed that the nasal footplate of the PRL was subluxated into the AC (Fig. 1), the subluxated PRL did not make contact with the corneal endothelium, so there was a minimal decrease of the endothelium cell counts in the injured eye. The PRL was repositioned successfully. Posterior dislocation of the PRL has been known to occur(2). Anterior subluxation is rarely reported. Anterior dislocation of the PRL in our case might be attributed to blunt trauma and a smaller PRL. This patient's WTW diameter was $12.6 \mathrm{~mm}$, and the PRL was implanted with a horizontal length of $11.3 \mathrm{~mm}$. Fechner recommended implanting oversized IOLs [adding $1.0 \mathrm{~mm}$ to the WTW diameter] (8), Marinho et al (9) support a short IOL diameter (1.0 mm shorter than WTW diameter).

As there is a risk of dislocation, there is a need to follow-up patients who have sustained ocular trauma and have implanted PRL, and further study of the stability and cataract formation rates is needed.

Case 2 represents pigment dispersion glaucoma after implantation with PRL. Implant movement and contact with the iris can cause pigment dispersion and a chronic inflammatory reaction. Pigmentary glaucoma and dispersion have been described after the implantation of Collamer(10) and silicone (5) PRLs. The dispersion of pigment could be from the continuous contact and friction between the PRL and the pigmented epithelium of the iris that would occur with iris movements and accommodation. The pigment dispersion may occur after an ocular trauma, intraocular lens implantation, iritis and so on (11), especially in Asians who have thicker and more heavily pigmented irises. There is convincing evidence found by Ultrasound biomicroscopythat contact between the PRL and the posterior iris surface occurred in all cases. The peripheral portion of the PRLs appeared to vault the peripheral iris forward, indicating contact between the PRL and the posterior iris (5). Over time, chronic pigment release can lead to elevated IOP and frank pigmentary glaucoma. So, determining the exact PRL size is crucial for the prevention of rubbing of the posterior surface of the iris with the PRL (12). We also posit that the chronic irritation of the posterior iris surface by the PRL disrupted the anterior blood-aqueous barrier, inducing anterior chamber inflammation. It is also possible that narrowing of the iridocorneal angle plays a role in the IOP increase. Pigmentary glaucoma is also associated with myopia, which is a strong risk factor for the development of open-angle glaucoma. Myopic subjects have a two-to-three fold increased risk of glaucoma compared to non-myopic subjects (13). This patient's WTW diameter was $12.3 \mathrm{~mm}$, while the PRL was implanted with a horizontal length of $11.3 \mathrm{~mm}$. Although it is a distinct possibility that the chosen PRL was oversized, this was not evident on standard preoperative measurement requirements. The pigmentary dispersion and PRL vault values provide the clue that this may be a potential issue.

The main advantages of PRL used for correction of high myopia are that the surgery is relatively simple, reversible, lens exchangeable, carries no risk of corneal endothelium contact, and does not depend on the vagaries of corneal wound healing or sacrifice of the crystalline lens and its accommodative ability (14). Despite these advantages, they also have some disadvantages; we summarized the case reports occurred worldwide (Table 1).

An oversized lens will cause undesirable vaulting, lead to pigment dispersion, chronic inflammatory reaction and pupillary block $(6,7)$; whereas an undersized lens can become decentred and increase the risk of dislocation and cataract. Tilting of the PRL has been reported in the early postoperative period due to the small size of the intraocular lens (21). Samar reported that a slightly undersized IOL diameter induced the combined optic decentration and cataract formation (22). Statistics from the original US Food and Drug Administration clinical trial for myopia suggest a replacement rate of $1.5 \%(8 / 523)$ due to symptomatic issues relating to over- or under-sizing of the pIOLs (23). Correct lens sizing (preciseness in sulcus-to-sulcus measurements) is mandatory to minimize the rate of complication. 
Table 1: Summary of case reports of the complications of posterior chamber phakic intraocular lens

\begin{tabular}{|c|c|c|c|c|c|}
\hline Study* & Country & Year & $\mathbf{n}$ & Complication & PC pIOL \\
\hline Masoud Soheilian $^{(15)}$ & USA & 2012 & 1 & Bilateral uveitis & ICL \\
\hline Espinosa-Mattar $Z^{(16)}$ & Mexico & 2012 & 1 & $\begin{array}{l}\text { Partially dislocated into } \\
\text { the anterior chamber and } \\
\text { corneal decompensation }\end{array}$ & ICL \\
\hline In Ki Park ${ }^{(12)}$ & Korea & 2008 & 1 & $\begin{array}{l}\text { Recurrent occlusion of } \\
\text { laser iridotomy sites }\end{array}$ & ICL \\
\hline Rafaek Navarro ${ }^{(17)}$ & Spain & 2005 & 1 & Bilateral Giant Retinal Tear & ICL \\
\hline Vicente Martinez-Castillo $^{(2)}$ & Spain & 2004 & 2 & $\begin{array}{l}\text { Dislocated into the vitreous } \\
\text { cavity }\end{array}$ & ICL \\
\hline Haralabos Eleftheriadis ${ }^{(18)}$ & Spain & 2004 & 1 & $\begin{array}{l}\text { Spontaneous dislocation into } \\
\text { the vitreous cavity }\end{array}$ & PRL \\
\hline Smallman $\mathrm{DS}^{(19)}$ & Canada & 2004 & 1 & Pupillary block glaucoma & PRL \\
\hline $\begin{array}{l}\text { Kodjikian } \mathrm{L}^{(20)} \\
\text { César A }\end{array}$ & France & 2002 & 1 & Malignant glaucoma & ICL \\
\hline Sánchez-Galeana ${ }^{(10)}$ & Mexico & 2002 & 1 & $\begin{array}{l}\text { Pigmentary glaucoma with } \\
\text { refractory IOL increase }\end{array}$ & ICL \\
\hline James D Brandt ${ }^{(5)}$ & USA & 2001 & 1 & $\begin{array}{l}\text { Induced Pigmentary } \\
\text { dispersion syndrome }\end{array}$ & ICL \\
\hline
\end{tabular}

*First author; PC: posterior chamber; pIOL: phakic intraocular lens; PRL: phakic refractive lens; ICL: implantable collamer lens

There are several lessons to be learned from these cases. First, correct lens sizing (preciseness in sulcus-tosulcus measurements) and a comprehensive ophthalmic evaluation were required to minimize the risk for potential complications (6). Second, Surgeons should have a careful preoperative evaluation, such as gonioscopy, to exclude the presence of glaucoma before performing any refractive procedures. It is necessary to inform myopic patients of their increased risk for glaucoma, seven years follow-up results for PRL are presented. Never-theless, the most important message is to take meticulous care to place PRL in every case and long-term follow-up is required.

\section{CONFLICTS OF INTEREST}

The authors have no proprietary interest in the material presented here.

\section{REFERENCES}

1. Kohnen T, Kook D, Morral M, Guell JL. Phakic intraocular lenses: part 2: results and complications. J Cataract Refract Surg 2010; 36: 2168-94.

2. Martinez-Castillo V, Elies D, Boixadera A, Garcia-Arumi J, Mauricio J, Cavero $\mathrm{L}$ et al. Silicone posterior chamber phakic intraocular lens dislocated into the vitreous cavity. J Refract Surg 2004; 20: 773-37.

3. Ju Y, Gao X, Ren B. Posterior chamber phakic intraocular lens implantation for high myopia. Int J Ophthalmol 2013; 6: 831-35.

4. Huang D, Schallhorn SC, Sugar A, Farjo AA, Majmudar PA, Trattler WB et al. Phakic intraocular lens implantation for the correction of myopia: a report by the American Academy of Ophthalmology. Ophthalmology 2009; 116: 2244-58.

5. Brandt JD, Mockovak ME, Chayet A. Pigmentary dispersion syndrome induced by a posterior chamber phakic refractive lens. Am J Ophthalmol 2001; 131: 260-63.

6. Tenen A, Roberts K, Sack J, Hodge C. Assessment of midperipheral anterior chamber depth in patient with posterior chamber phakic intraocular lens. J Cataract Refract Surg 2013; 39: 1611-4.
7. Chan KC, Birchall W, Gray TB, Wells AP. Acute angle closure after implantable contact lens insertion unresponsive to surgical peripheral iridectomy. J Cataract Refract Surg 2008; 34: 696-9.

8. Fechner PU. Cataract formation with a phakic IOL. J Cataract Refract Surg 1999; 25: 461-2.

9. Marinho A, Neves MC, Pinto MC, Vaz F. Posterior chamber silicone phakic intraocular lens. J Refract Surg 1997; 13: 219-22.

10. Sanchez-Galeana CA, Zadok D, Montes M, Cortes MA, Chayet AS. Refractory intraocular pressure increase after phakic posterior chamber intraocular lens implantation. Am J Ophthalmol 2002; 134: 121-23.

11. Niyadurupola N, Broadway DC. Pigment dispersion syndrome and pigmentary glaucoma - a major review. Clin Experiment Ophthalmol 2008; 36: $868-82$.

12. Park IK, Lee JM, Chun YS. Recurrent occlusion of laser iridotomy sites after posterior chamber phakic IOL implantation. Korean J Ophthalmol 2008; 22: 130-2.

13. Mitchell P, Hourihan F, Sandbach J, Wang JJ. The relationship between glaucoma and myopia: the Blue Mountains Eye Study. Ophthalmology 1999; 106: 2010-5.

14. Lackner B, Pieh S, Schmidinger G, Simader C, Franz C, Dejaco-Ruhswurm I et al. Long-term results of implantation of phakic posterior chamber intraocular lenses. J Cataract Refract Surg 2004; 30: 2269-76.

15. Soheilian M, Jabbarpourbonyadi M, Soheilian R, Peyman GA. Bilateral uveitis after phakic intraocular lens implantation and management with adalimumab. J Cataract Refract Surg 2012; 38: 1094-6.

16. Espinosa-Mattar Z, Gomez-Bastar A, Graue-Hernandez EO, Navas A. DSAEK for implantable collamer lens dislocation and corneal decompensation 6 years after implantation. Ophthalmic Surg Lasers Imaging 2012; 43: e68-72.

17. Navarro R, Gris $\mathrm{O}$, Broc L, Corcostegui B. Bilateral giant retinal tear following posterior chamber phakic intraocular lens implantation. J Refract Surg 2005; 21: 298-300.

18. Eleftheriadis H, Amoros S, Bilbao R, Teijeiro MA. Spontaneous dislocation of a phakic refractive lens into the vitreous cavity. J Cataract Refract Surg 2004; 30: 2013-6.

19. Smallman DS, Probst L, Rafuse PE. Pupillary block glaucoma secondary to posterior chamber phakic intraocular lens implantation for high myopia. J Cataract Refract Surg 2004; 30: 905-7.

20. Kodjikian L, Gain P, Donate D, Rouberol F, Burillon C. Malignant glaucoma induced by a phakic posterior chamber intraocular lens for myopia. J Cataract Refract Surg 2002; 28: 2217-21. 
21. Hoyos JE, Dementiev DD, Cigales M, Hoyos-Chacon J, Hoffer KJ. Phakic refractive lens experience in Spain. J Cataract Refract Surg 2002; 28: 1939-46.

22. Al-Swailem SA, Al-Rajhi AA. Decentration and cataract formation 10 years following posterior chamber silicone phakic intraocular lens implantation. J Refract Surg 2006; 22: 513-5.
23. Sanders DR, Vukich JA, Doney K, Gaston M. Implantable Contact Lens in Treatment of Myopia Study Group. Ophthalmology 2003; 110: 255-66. 